\title{
Correction to: Deterioration of Porcelain Insulators Utilized in Overhead Transmission Lines: A Review
}

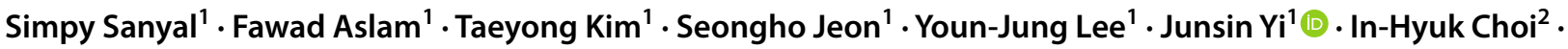 \\ Ju-Am Son ${ }^{2} \cdot$ Ja-Bin Koo ${ }^{2}$
}

Published online: 26 December 2019

(c) The Korean Institute of Electrical and Electronic Material Engineers 2019

\section{Correction to: \\ Transactions on Electrical and Electronic Materials https://doi.org/10.1007/s42341-019-00143-5}

The article Deterioration of Porcelain Insulators Utilized in Overhead Transmission Lines: A Review, written by Simpy Sanyal, Fawad Aslam, Taeyong Kim, Seongho Jeon, YounJung Lee, Junsin Yi, In-Hyuk Choi, Ju-Am Son and Ja-Bin Koo was originally published electronically on the publisher's internet portal (currently SpringerLink) on 19 September 2019 with open access. With the author(s)' decision to step back from Open Choice, the copyright of the article changed on 24 December 2019 to (C) The Korean Institute of
Electrical and Electronic Material Engineers 2019 and the article is forthwith distributed under the terms of copyright.

The original article has been corrected.

Publisher's Note Springer Nature remains neutral with regard to jurisdictional claims in published maps and institutional affiliations.

The original article can be found online at https://doi.org/10.1007/ s42341-019-00143-5.

Junsin Yi

junsin@skku.edu

1 School of Electronic and Electrical Engineering, Sungkyunkwan University, Suwon 03063, Republic of Korea

2 KEPCO Research Institute, Daejeon 34056, Republic of Korea 